\title{
ASSESSMENT OF PROXIMITY OF MAXILLARY MOLARS ROOTS TO THE MAXILLARY SINUS FLOOR IN A SAMPLE FROM THE EGYPTIAN POPULATION USING CONE-BEAM COMPUTED TOMOGRAPHY (HOSPITAL BASED STUDY)
}

\author{
Enas Anter*, Yara Helaly* and Walaa Samir ${ }^{* *}$
}

\begin{abstract}
Aim: To assess the proximity between the roots of maxillary molars and Maxillary Sinus Floor 'MSF' using CBCT in a sample from the Egyptian population.

Materials and Methods: Eighty seven CBCT scans of adult Egyptians (29 males and 58 females) involving 135 maxillary $1^{\text {st }}$ molars, 168 maxillary $2^{\text {nd }}$ molars and 107 maxillary $3^{\text {rd }}$ molars, were collected from patients' data base of Planmeca Promax 3D Mid CBCT machine available at the Department of Oral \&Maxillofacial Radiology, Faculty of Dentistry, Cairo University. The vertical relation between MSF and examined teeth roots was assessed on cross sectional CBCT images based on Jung classification 2009
\end{abstract}

Results: In all mesio-buccal 'MB', disto-buccal 'DB'\& palatal 'P' roots of the examined teeth, the $1^{\text {st }}$ molars showed the highest prevalence of class $(0)$ in the 3 roots, while the $2^{\text {nd }}$ molars showed the highest prevalence of class (3) among both MB \& DB roots, and the highest prevalence of class (2) among P roots, finally $3^{\text {rd }}$ molars showed the highest prevalence of class (1) among DB roots, and the highest prevalence of class (3) among P roots. There was a significant inverse correlation between age and vertical relationship classes of only the first maxillary molars roots. Males showed higher prevalence of Class (2) and Class (3) while females showed higher prevalence of Class (0) and Class (1) in the $3^{\text {rd }}$ molars.

Conclusion: In the investigated Egyptian subjects, maxillary $1^{\text {st }}$ molars' roots are the least close to the MSF compared to the other molars roots, while buccal roots of maxillary $2^{\text {nd }}$ molars are highly anticipated for MSF invagination. The lower the age is, the closer are the maxillary $1^{\text {st }}$ molar roots to the MSF, and males' maxillary $3^{\text {rd }}$ molars are more frequently approximating MSF than females.

KEYWORDS: Maxillary Sinus, CBCT, Maxillary Molars.

* Lecturer of Oral and Maxillofacial Radiology Cairo University

** Lecturer of Oral and Maxillofacial Radiology Bani-suaif University 


\section{INTRODUCTION}

Among all paranasal sinuses, the largest and the first one to develop which is the maxillary sinus has received special concerns from all the dentists worldwide. It was first illustrated by Leonardo da Vinci in 1489 and later documented and described by the English anatomist Nathaniel Highmore in $1651^{1}$. Maxillary sinus is pyramidal in shape with its floor formed by both alveolar and palatine processes of maxilla representing the boundary between maxillary sinus and oral cavity ${ }^{2,3}$. Proximity of maxillary posterior teeth roots to the floor of the maxillary sinus is an important anatomical consideration that should be well cogitated $^{3,4,5}$, as the closer the roots of the teeth to the sinus floor, the higher the probability of spread of odontogenic infection to maxillary sinus causing inflammatory changes of its mucosal lining and bringing about maxillary sinusitis ${ }^{6-9}$. Moreover, a perforation of maxillary sinus floor with a resultant oro-antral communication could be a sequela of posterior tooth extraction that has roots very close to the sinus floor which further complicate the tooth replacement procedures via dental implant treatment and may require grafting procedures ${ }^{10,11}$. Therefore, it is crucial to assess the relationship between posterior teeth roots and MSF before planning any dental treatment procedure in this region to avoid procedural complications.

With evolution and advancement of CBCT it widely replaced conventional $2 \mathrm{D}$ radiographs for assessment of the teeth prior to various dental treatment procedures especially in endodontics, implant planning and planning for minor oral surgeries, which all require considering the proximity of the teeth to nearby vital structures, with special concerns paid to MSF relation to maxillary molars ${ }^{11-16}$. For that, this study was conducted to assess the proximity between the roots of maxillary molars and Maxillary Sinus Floor 'MSF' using CBCT in a sample from the Egyptian population.

\section{MATERIALS AND METHODS}

The current study design was an observational retrospective one. A sample size calculation was made prior to conducting the study using Epi Info 7.2.2.2 based on the results of a previous study by Fry et al. 2016 ${ }^{17}$, with alpha $(\alpha)$ level of $(5 \%)$ and acceptable margin of error $=2 \%$ giving a total sample size of 86 CBCT scans for Egyptian subjects to be included within the study design. The required scans were collected from the database of Oral and Maxillofacial Radiology Department, Faculty of Dentistry, Cairo University in the period from Jan 2019 to June 2019.They were all acquired using Planmeca Romexis $3 D$ Mid CBCT machine with $0.4 \mathrm{~mm}$ voxel size and FOV of either single arch (maxilla) or double arches. Selection of the scans to be included was based on the following eligibility criteria; the scans were for Egyptian subjects not younger than 18 years old and with fully erupted maxillary molars with fully formed roots free from apical resorption or root fracture. While the exclusion criteria included; scans with any bony changes associated with cystic or neoplastic lesions in the posterior area of the maxilla and/or maxillary sinus, presence of signs of previous surgery in the maxillary sinus, scans with metallic artifacts obscuring visibility of the maxillary molars apices or MSF.

The included CBCT scans were for 29 males and 58 females with a mean age of 34.8 years (range: $18-67$ years) involving 135 maxillary $1^{\text {st }}$ molars, 168 maxillary $2^{\text {nd }}$ molars and 107 maxillary $3^{\text {rd }}$ molars.

The data of this study included: $\boldsymbol{a}$ - Demographic Data: Presented in the personal information of the patients including; name, age, gender and purpose of the scan. This data was tabulated for each scan that was then coded with a number which was kept hidden from the researchers who carried out the radiographic analysis procedures. $\boldsymbol{b}$ - Radiographic Data: Represented by CBCT images that were viewed and analyzed using Planmeca Romexis Viewer Launcher version 4.6.2.R, 
Coronal and sagittal cross sectional CBCT images with $0.4 \mathrm{~mm}$ slice thickness and $0.4 \mathrm{~mm}$ interslice distance were used for assessment of the vertical proximity of maxillary molar root tips to MSF but after being corrected to be passing with the long axis of each root under investigation, this anatomical relationship was classified into four types based on 'Jung classification 2009' '18 (Figure 1).

Type 0: The maxillary sinus floor is located above the root apex (Fig. 2).

Type 1: The root apex touches the floor of maxillary sinus (Fig. 3).

Type 2: The floor of maxillary sinus is interposed between roots (Fig.4).
Type 3: Apical protrusion is observed over the maxillary sinus floor. (Fig.5).

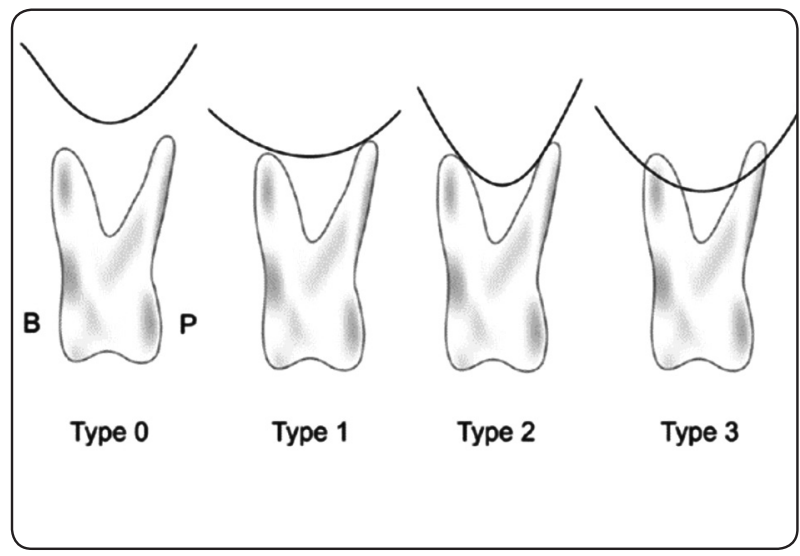

Fig. (1) Jung classification 2009 of MSF vertical relation with posterior teeth root apices.

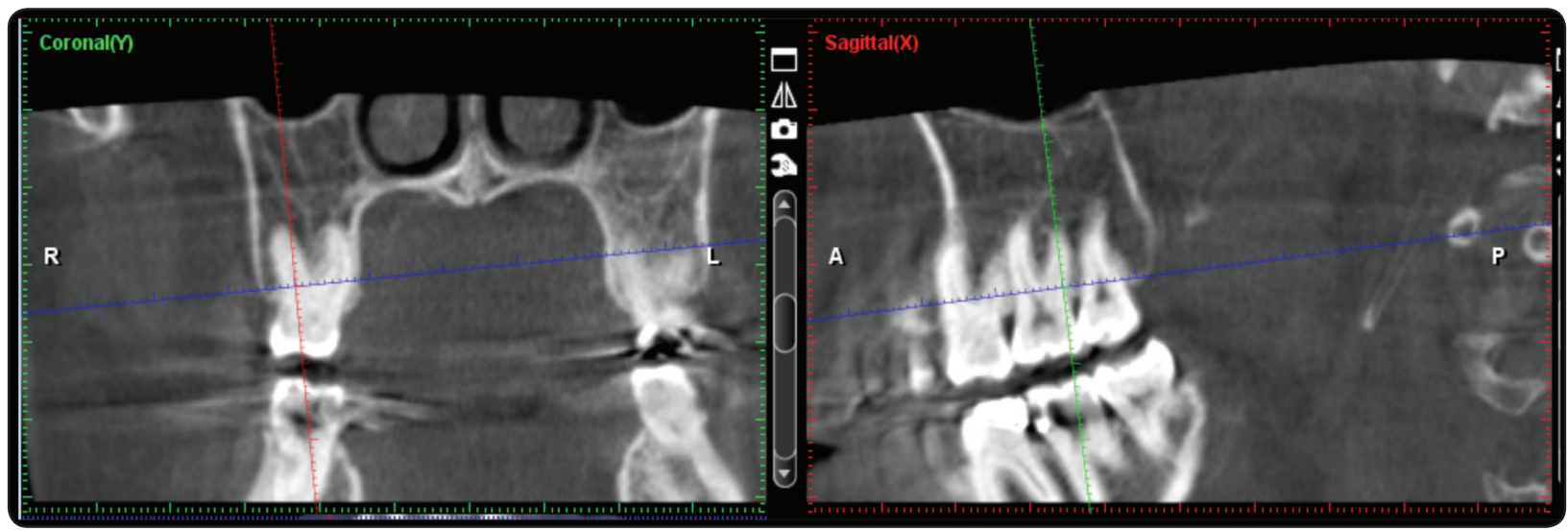

Fig. (2) CBCT scan on Planmeca Romexis viewer screen showing corrected coronal and sagittal CBCT images passing with the long axis of DB root of upper right 2 nd molar that showed type 0 relation with MSF

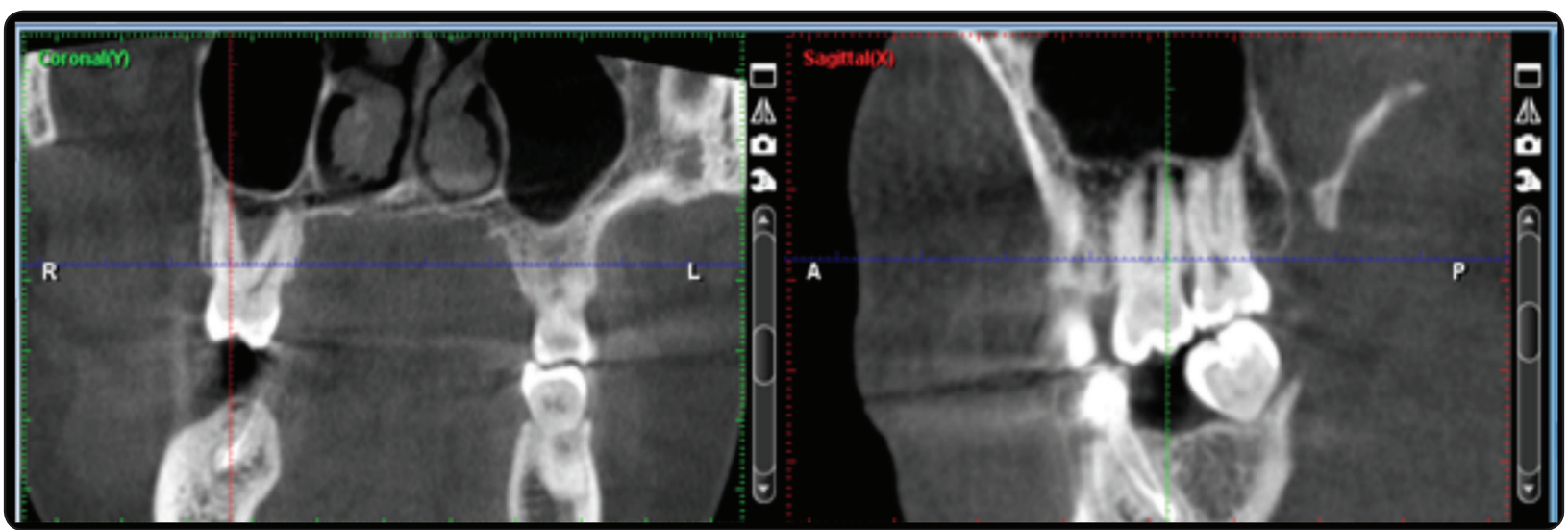

Fig. (3) CBCT scan on Planmeca Romexis viewer screen showing corrected coronal and sagittal CBCT images passing with the long axis of DB root of upper right 2nd molar that showed type 1 relation with MSF. 


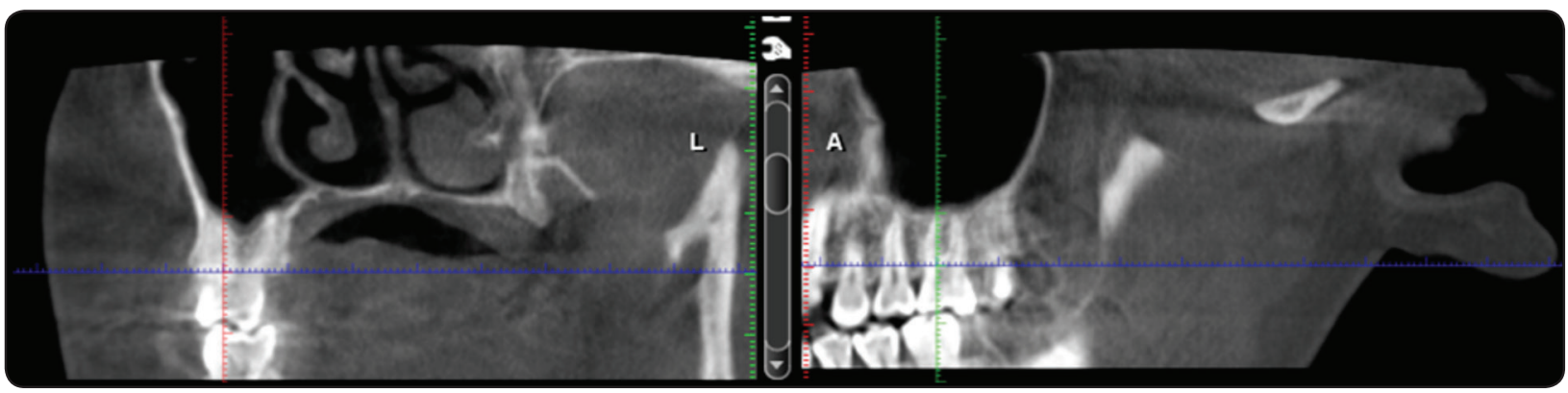

Fig. (4) CBCT scan on Planmeca Romexis viewer screen showing corrected coronal and sagittal CBCT images passing with the long axis of MB root of upper right 1st molar that showed type 2 relation with MSF for MB root and type 3 relation for the palatal root.

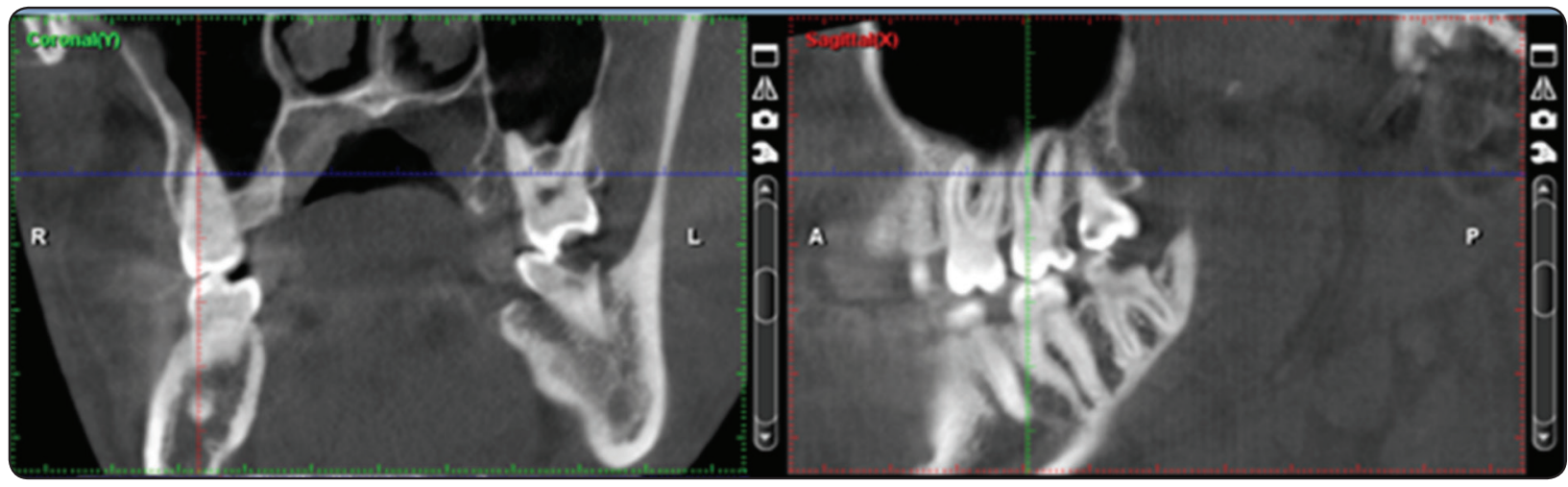

Fig. (5) CBCT scan on Planmeca Romexis viewer screen showing corrected coronal and sagittal CBCT images passing with the long axis of MB root of upper right 2nd molar that showed type 3 relation with MSF for MB root of Rt 2nd molar, and MB \& palatal roots of $\mathrm{Lt} 2$ nd molar.

Image analysis procedures were all done by two researchers with 10 years of experience in CBCT images interpretation. After finalization of all the assessment procedures, the raw data was delivered to the third researcher who unveiled the codes of the scans for tabulation of the data in an Excel sheet including the demographic data of the scanned patient (Name, Age, Gender).

\section{Statistical Analysis}

Age and gender data were presented as mean and standard deviation (SD) values. Qualitative data were presented as frequencies and percentages. Friedman's test was used to compare between vertical relationship classes among first, second and third molars. Multivariate regression analysis was performed to determine the effect of age and gender on vertical relationship classes. Spearman's correlation coefficient was used to determine the correlation between age and classes. Chi-square test was used for comparison between males and females. The significance level was set at $\mathrm{P} \leq 0.05$. Statistical analysis was performed with IBM SPSS Statistics for Windows, Version 23.0. Armonk, NY: IBM Corp.

\section{RESULTS}

The present study was conducted on 87 scans belonging to 87 subjects; 29 males (33.3\%) and 58 females (66.7\%). The mean (SD) values for age were 34.8 (11.7) years with a minimum of 15 and a maximum of 67 years. Number of teeth included in the study was 135 maxillary first permanent molars, 168 maxillary second molars and 107 maxillary third molars. 


\section{A. Comparison between first, second and third} maxillary molars

As regards $\mathrm{MB}$ root; there was a statistically significant difference between the permanent molars, where the $1^{\text {st }}$ molar showed the highest prevalence of type (0) \& (2) and $2^{\text {nd }}$ molar showed the highest prevalence of type (1) \& (3). While for DB root; there was no statistically significant difference between the permanent molars where the $1^{\text {st }}$ molar showed the highest prevalence of type
(0) \& (2), $2^{\text {nd }}$ molar showed the highest prevalence of type (3) and the $3^{\text {rd }}$ molar showed the highest prevalence of type (1). Finally, as regards Palatal root; there was no statistically significant difference between the permanent molars, as the $1^{\text {st }}$ molar showed the highest prevalence of type (0) \& (2) and $2^{\text {nd }}$ molar showed the highest prevalence of type (1) and the $3^{\text {rd }}$ molar showed the highest prevalence of type (3) (Table 1 \& Fig. 6)

TABLE (1) Frequencies, percentages (\%) and results of Friedman's test for comparison between classification of vertical relationship between root apex of maxillary posterior teeth and maxillary sinus floor in the study sample.

\begin{tabular}{|c|c|c|c|c|c|c|c|c|c|}
\hline \multirow{2}{*}{\multicolumn{2}{|c|}{ Root }} & \multicolumn{2}{|c|}{$\begin{array}{l}\text { First molar } \\
(\mathrm{n}=135)\end{array}$} & \multicolumn{2}{|c|}{$\begin{array}{l}\text { Second molar } \\
\qquad(\mathrm{n}=168)\end{array}$} & \multicolumn{2}{|c|}{$\begin{array}{l}\text { Third molar } \\
(\mathrm{n}=107)\end{array}$} & \multirow[t]{2}{*}{$P$-value } & \multirow[t]{2}{*}{ Effect size ( $w)$} \\
\hline & & $\mathrm{N}$ & $\%$ & $\mathrm{n}$ & $\%$ & $\mathrm{n}$ & $\%$ & & \\
\hline \multicolumn{10}{|c|}{ Mesio-Buccal } \\
\hline & Class 0 & $61 / 135$ & 45.2 & $36 / 168$ & 21.4 & $39 / 107$ & 36.4 & \multirow{4}{*}{$0.009 *$} & \multirow{4}{*}{0.044} \\
\hline & Class 1 & $39 / 135$ & 28.9 & $72 / 168$ & 72.9 & $42 / 107$ & 39.3 & & \\
\hline & Class 2 & $17 / 135$ & 12.6 & $8 / 168$ & 4.8 & $3 / 107$ & 2.8 & & \\
\hline & Class 3 & $18 / 135$ & 13.3 & $52 / 168$ & 31 & $23 / 107$ & 21.5 & & \\
\hline \multicolumn{10}{|c|}{ Disto-Buccal } \\
\hline & Class 0 & $57 / 135$ & 42.2 & $53 / 168$ & 31.5 & $41 / 107$ & 38.3 & \multirow{4}{*}{0.537} & \multirow{4}{*}{0.006} \\
\hline & Class 1 & $41 / 135$ & 30.4 & $63 / 168$ & 37.5 & $44 / 107$ & 41.1 & & \\
\hline & Class 2 & $22 / 135$ & 16.3 & $15 / 168$ & 8.9 & $1 / 107$ & 0.9 & & \\
\hline & Class 3 & $15 / 135$ & 11.1 & $37 / 168$ & 22 & $21 / 107$ & 19.6 & & \\
\hline \multicolumn{10}{|c|}{ Palatal } \\
\hline & Class 0 & $62 / 135$ & 45.9 & $58 / 168$ & 34.5 & $47 / 107$ & 43.9 & \multirow{4}{*}{0.790} & \multirow{4}{*}{0.002} \\
\hline & Class 1 & $33 / 135$ & 24.4 & $66 / 168$ & 39.3 & $34 / 107$ & 31.8 & & \\
\hline & Class 2 & $20 / 135$ & 14.8 & $20 / 168$ & 11.9 & $4 / 107$ & 3.7 & & \\
\hline & Class 3 & $20 / 135$ & 14.8 & $24 / 168$ & 14.3 & $22 / 107$ & 20.6 & & \\
\hline
\end{tabular}

*: Significant at $P \leq 0.05$ 


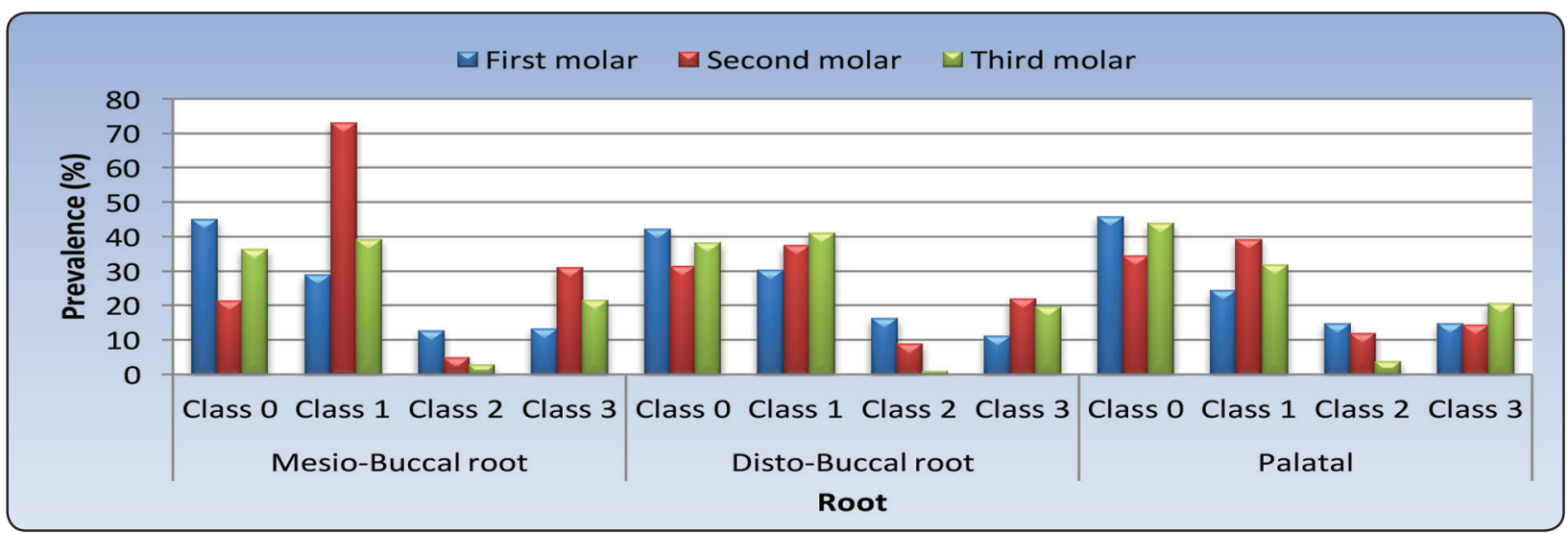

Fig. (6) Bar chart representing comparison between maxillary molars regarding the prevalence of different types of vertical relationship with MSF in the study sample

\section{B. Multivariate regression analysis}

Multivariate regression analysis model was constructed using the relationship types of different roots as the dependent variable while gender and age were the covariates.

Regression analysis results revealed that age was a significant predictor for the vertical relationship between root apices of maxillary first molar and MSF. There was an inverse correlation between age and vertical relationship classes of first maxillary molar roots. While regards $2^{\text {nd }}$ and $3^{\text {rd }}$ molar Age was not a statistically significant predictor for the vertical relationship between root apices and MSF (Table 2).

Gender was found to be a statistically significant predictor for the vertical relationship between DistoBuccal root apex of maxillary third molar and MSF. Males showed higher prevalence of Class (2) and Class (3) while females showed higher prevalence of Class (0) and Class (1) (Tables $2 \mathbf{\& 3}$ ).

TABLE (2) Multivariate regression analysis results for the effect of age and gender on vertical relationship between root apex of maxillary posterior teeth and maxillary sinus floor

\begin{tabular}{|c|c|c|c|c|c|c|c|}
\hline $\begin{array}{l}\text { Source of } \\
\text { variation }\end{array}$ & $\begin{array}{l}\text { Dependent } \\
\text { variables }\end{array}$ & Sum of Squares & Df & Mean Square & $P$-value & $P$-value & $\begin{array}{c}\text { Effect size } \\
\text { (Partial Eta } \\
\text { Squared) }\end{array}$ \\
\hline \multirow{9}{*}{ Age } & MB root of U6 & 20.233 & 1 & 20.233 & 21.375 & $<0.001 *$ & 0.170 \\
\hline & DB root of U6 & 21.104 & 1 & 21.104 & 24.187 & $<0.001 *$ & 0.189 \\
\hline & P root of U6 & 22.915 & 1 & 22.915 & 23.399 & $<0.001 *$ & 0.184 \\
\hline & MB root of $U 7$ & 0.280 & 1 & 0.280 & 0.227 & 0.634 & 0.002 \\
\hline & DB root of U7 & 0.166 & 1 & 0.166 & 0.144 & 0.705 & 0.001 \\
\hline & P root of U7 & 0.162 & 1 & 0.162 & 0.180 & 0.672 & 0.002 \\
\hline & MB root of U8 & 2.529 & 1 & 2.529 & 2.079 & 0.152 & 0.020 \\
\hline & DB root of U8 & 2.528 & 1 & 2.528 & 2.219 & 0.139 & 0.021 \\
\hline & P root of U8 & 2.861 & 1 & 2.861 & 2.246 & 0.137 & 0.021 \\
\hline
\end{tabular}




\begin{tabular}{|c|c|c|c|c|c|c|c|}
\hline $\begin{array}{l}\text { Source of } \\
\text { variation }\end{array}$ & $\begin{array}{c}\text { Dependent } \\
\text { variables }\end{array}$ & Sum of Squares & Df & Mean Square & $P$-value & $P$-value & $\begin{array}{c}\text { Effect size } \\
\text { (Partial Eta } \\
\text { Squared) }\end{array}$ \\
\hline \multirow{9}{*}{ Gender } & MB root of U6 & 2.154 & 1 & 2.154 & 2.275 & 0.134 & 0.021 \\
\hline & DB root of U6 & 0.339 & 1 & 0.339 & 0.388 & 0.535 & 0.004 \\
\hline & P root of U6 & 0.077 & 1 & 0.077 & 0.079 & 0.779 & 0.001 \\
\hline & MB root of U7 & 2.855 & 1 & 2.855 & 2.323 & 0.131 & 0.022 \\
\hline & DB root of U7 & 0.414 & 1 & 0.414 & 0.358 & 0.551 & 0.003 \\
\hline & P root of U7 & 1.459 & 1 & 1.459 & 1.624 & 0.205 & 0.015 \\
\hline & MB root of U8 & 4.884 & 1 & 4.884 & 4.016 & 0.051 & 0.037 \\
\hline & DB root of U8 & 5.851 & 1 & 5.851 & 5.135 & $0.026^{*}$ & 0.047 \\
\hline & P root of U8 & 4.529 & 1 & 4.529 & 3.555 & 0.062 & 0.033 \\
\hline
\end{tabular}

*: Significant at $P \leq 0.05$

TABLE (3) Frequencies, percentages (\%) and results of Chi-square test for the association between gender and classification of vertical relationship of Disto-Buccal root apex of maxillary third molar and maxillary sinus

\begin{tabular}{lccccc}
\hline & \multicolumn{2}{c}{ Males } & \multicolumn{2}{c}{ Females } \\
Root & $(\mathrm{n}=21$ molars $)$ & \multicolumn{2}{c}{$(\mathrm{n}=86$ molars $)$} & $P$-value \\
& $\mathrm{n}$ & $\%$ & $\mathrm{n}$ & $\%$ & \\
\hline Disto-Buccal & & & & & \\
Class 0 & $5 / 21$ & 23.8 & $36 / 86$ & 41.9 & \\
Class 1 & $8 / 21$ & 38.1 & $36 / 86$ & 41.9 & $0.044^{*}$ \\
Class 2 & $1 / 21$ & 4.8 & $0 / 86$ & 0 & \\
Class 3 & $7 / 21$ & 33.3 & $14 / 86$ & 16.3 & \\
\hline
\end{tabular}

*: Significant at $P \leq 0.05$

\section{DISCUSSION}

Maxillary sinus or the antrum of Highmore is a very familiar anatomic structure to the dentists, it is greatly considered in most of the dental procedures involving maxillary posterior teeth. However, the current study targeted mainly the vertical relation between maxillary molars \& MSF, we didn't consider the premolars, as most of the anatomical studies which described the maxillary sinus topography found that the deepest point of MSF is commonly located in the area of $1^{\text {st }}$ and $2^{\text {nd }}$ molars and they also reported that maxillary molars are generally closer to MSF than maxillary premolars ${ }^{19,20}$.

Proximity of maxillary posterior teeth to MSF have been previously assessed using conventional 2D periapical \& panoramic radiographs ${ }^{21}$, but unfortunately their drawbacks represented in multiple anatomic superimposition and geometrical errors rendered them none reliable in this issue ${ }^{22,23}$. However, introduction of CT in dental field has solved this problem by providing accurate 3D tomographic images for better anatomic correlation of maxillary posterior teeth roots and $\mathrm{MSF}^{24}$.

CBCT has revolutionized the dental diagnosis and treatment procedures, it solved a lot of diagnostic dilemmas in dentistry by providing $3 \mathrm{D}$ images with a lower cost and lower radiation exposure to patients compared to conventional $\mathrm{CT}^{25,26}$. It also provides variable fields of view ' $\mathrm{FOV}$ ' and a sub-millimeteric isotropic voxel resolution, which allows the non-orthogonal sectioning of the obtained data sets providing variable display modes allowing it to be used in variable dental fields ${ }^{25,26}$. 
The literature is full of reports about complications that resulted from performing different dental treatment procedures in maxillary molars region without considering their proximity to MSF, as in 2006, Huang and Brunsvold ${ }^{27}$ reported a case with maxillary sinusitis developed as a sequela of periodontal treatment procedures for deep pocket in maxillary $1^{\text {st }}$ molar that is closely related to $\mathrm{MSF}^{27}$, similar findings were reported in 2012 by Brüllmann et al. ${ }^{28}$ who found a mucosal thickening in the sinus floor in cases of decayed or periodontally affected maxillary molars closely related to $\mathrm{MSF}^{28}$. A different case report was found describing presence of impression material inside the sinus that has been pushed through an unseen oro-antral communication that resulted following extraction of maxillary molar closely related to $\mathrm{MSF}^{29}$. Moreover, a case of orbital abscess developed 48 hours following root canal treatment (RCT) of maxillary $1^{\text {st }}$ molar closely related to MSF has been reported by Koch et $\boldsymbol{a l}^{30}$.

Searching the literature for studies discussing the proximity of maxillary molars roots to MSF using CBCT, several studies have been found but none of them was conducted on Egyptian subjects. Hence, as long as differences in ethnicity characteristics could invite diversity in such anatomical relationship ${ }^{31}$, it was mandatory to assess this relationship in Egyptian subjects to explore the similarity with the other examined populations.

Different ways have been used by the researches worldwide in describing the proximity of posterior teeth to MSF, as in $2004 \mathbf{K w a k}$ et $\boldsymbol{a l}^{32}$. proposed a classification for vertical relationship between maxillary posterior teeth and MSF in Korean population using CT images, this classification composed of five relationship types that were denoted by Latin numbers I, II, II, III, IV \&V, where the greater the type number the closer are the roots to MSF, this classification has been used later by Estrela et al. 2016 ${ }^{31}$ for assessment of this relationship in Brazilian population using CBCT.
While in 2009 Jung et al $^{18}$ postulated a classification on CBCT images, this classification was used in the current study and in other previous studies including those of Jung et al. 2012 ${ }^{33}$, Shokri et al. 2014 $^{34}$ and Fry et al $2016^{17}$, where all utilized CBCT in the evaluation except for Fry et al ${ }^{17}$ who utilized CT images. Jung $2009^{18}$ classification as described in the methodology section is composed of 4 types denoted by numbers $0,1,2 \& 3$, where the greater the type number the closer are the roots to MSF.

However, another different classification was done by Kilic et al. 2010 ${ }^{35}$ who classified the targeted relationship on CBCT images to only three types $1,2 \& 3$ with type 1 representing roots penetrating MSF, type 2 representing roots contacting MSF and type 3 representing roots not reaching MSF, then this classification was used again by $\boldsymbol{O} \boldsymbol{k}$ et al. 2014 ${ }^{36}$ on CBCT images of Turkish population.

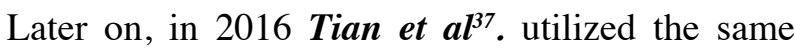
vertical relationship types of Kilic $^{35}$ in Chinese population CBCT, but they named these types by letters (IS), (CO) \& (OS) which corresponds to types $1,2 \& 3$ respectively, and again the same way of classification was used in 2018 by $\boldsymbol{G u} \boldsymbol{e t} \boldsymbol{a} \boldsymbol{l}^{38}$. on $\mathrm{CBCT}$ of Chinese population also.

A classification formed of 5 types was proposed by Didilescu et al. $2012^{39}$ illustrating the vertical relationship between maxillary $1^{\text {st }}$ molar roots and MSF on CBCT images, the 5 types were referred to by numbers $0,1,2,3 \& 4$ with the higher the type number the more the distance is from the MSF, similarly Shokry et al. $\mathbf{2 0 1 6}^{40}$ utilized the same classification in classifying only maxillary $1^{\text {st }}$ molar roots relation to MSF using CBCT images. However, Pagin et al. $2013^{41}$ have differently classified the targeted relationship in Brazilian population as they originally classified their included CBCT scans to scans with no MSF approximation \& scans with MSF approximation, then the later were classified to group 1 (Gp1) with molars roots not elevating MSF\& group 2 (Gp 2) with molars roots elevating 
the MSF. Finally, Asthana et al $2015^{42}$ assessed the vertical relationship between maxillary molars root and MSF via distance measurements on CBCT images with assigning negative values for roots penetrating MSF.

The results of this study showed that in the examined Egyptian subjects, the $1^{\text {st }}$ molar was the least close molar to the MSF with the highest prevalence of class 0 in all of MB, DB \& palatal roots which coincides with the findings of Kwak et $\boldsymbol{a l}^{32}$ study that was conducted on 33 Korean heads imaged with CT. They found that the distances between the maxillary posterior teeth roots apices and the MSF are reduced the more posterior we go. Similarly to ours and to $\mathbf{K w a k s}^{32}$, results, Pagin et $\boldsymbol{a \boldsymbol { l } ^ { 4 1 }}$. also found that maxillary $1^{\text {st }}$ molar was the least close molar to MSF in their study conducted on 50 CBCT scans of Brazilian patients. Again, Tian et al. $2016^{37}$ reported the same finding in their study conducted on 884 CBCT scans of Chinese patients.

While Asthana et al $2015^{42}$ \& Ok et al. $2014^{36}$ both found that only buccal roots of maxillary $1^{\text {st }}$ molars had the highest prevalence of being distant from the MSF with the $1^{\text {st }}$ study conducted on 30 maxillary $1^{\text {st }}$ molar\& 30 maxillary $2^{\text {nd }}$ molar in 17 CBCT scans, while the last one conducted on 2488 molars in 849 CBCT scans of Turkish subjects. This result was partly contradicting our findings as they found that the palatal root of maxillary $1^{\text {st }}$ molar had the highest prevalence of being inside the sinus, a finding that was also reported by $G \boldsymbol{u}$ et $\mathbf{a l} .2018^{38}$ and Estela et al. $2016^{31}$ unlike us.

The highest prevalence of MSF penetration 'type 3' in the current study was recorded for buccal roots of maxillary $2^{\text {nd }}$ molars and this finding was matching those of Kilic $2010^{5}$, Pagin 201341, Jung $2012^{33}$, Asthana $2015^{42}$ \& Tian $2016^{37}$. However , partial correspondence was found between our finding in this point and those of $\boldsymbol{G u} 2018^{38}$ and Estela $2016^{31}$ as both of them found that the palatal root of $1^{\text {st }}$ maxillary molar is sharing the buccal roots of $2^{\text {nd }}$ maxillary molars in the highest prevalence of
MSF penetration. Yet, Shokri et al $2014^{34}$ reported that both maxillary $1^{\text {st }}$ molar $\& 2^{\text {nd }}$ molar had the highest prevalence of MSF penetration without differentiating the roots affection.

There was a consensus from all the studies that assessed the vertical relationship between all maxillary posterior teeth (including the premolars) and MSF that the premolars' roots were more distant

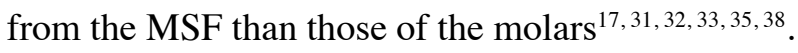

Our explanation for the diversity between the studies in their findings of which root is the closest and which is the most far from the MSF could be attributed to the differences in the number of patients included in both studies, their gender distribution, their age ranges, the evaluation method and the ethnicity characteristics of the examined populations.

Regarding the association between the age of the subjects and the targeted vertical relationship types, the results of the current study showed that age was a significant predictor for the vertical relationship between root apices of maxillary $1^{\text {st }}$ molar only and the MSF, as there was an inverse correlation between the age and vertical relationship types, as type 0 with less sinus approximation was more frequent in older subjects while type 3 with MSF invasion was more common in younger subjects. Comparing this finding to the previously conducted studies, we found only six studies addressing this issue in their results, where a similar inverse correlation between age and maxillary sinus approximation was reported by Didilescu et al. $2012^{39}$ in maxillary $1^{\text {st }}$ molars also which were solely examined in this paper. Furthermore, Tian et al. $2016^{37}$ \& Gu et al. $2018^{38}$ reported the same correlation but not exclusive in maxillary $1^{\text {st }}$ molars. However, a partial coincidence was found between our results and those of Shokry et al $2016^{40} \&$ Ok et al $2014^{36}$, as the $1^{\text {st }}$ study concluded that the distance between the buccal roots only of maxillary $1^{\text {st }}$ molars and the MSF is increased in higher age groups, while the palatal roots of these molars are more commonly approximating MSF in 
older age subjects. Meanwhile, the $2^{\text {nd }}$ study reported similarly to us an inverse correlation between MSF approximation by maxillary molars roots and the age of the subjects. They added that this relation was limited to the first 3 decades of life, while in subjects older than 60 years old they found higher prevalence of MSF invagination by molars roots.

The explanation of our age correlation finding could be attributed to the anatomical fact that the physiological volume increase of the maxillary sinus by pneumatization commonly ends with the completion of the eruption of maxillary third molars usually by the age of $21-30$, afterward, sinus volume start to decrease ${ }^{43,}{ }^{44}$. However, pneumatization of maxillary sinus is also affected by many other factors rather than age, like hereditary factors, growth hormones, air pressure inside the sinus and posterior teeth extraction ${ }^{45,46,47,48}$. The last cause could be the one that resulted in the reverse of our relation in the patients older than 60 in $\boldsymbol{O k}$ et $\boldsymbol{a l}^{36} \mathbf{s t u d y}$, as this could be due to the common teeth extraction after this age.

On the other hand, Pagin et al $2013^{41}$ found no correlation between age of the subjects \& maxillary molars vertical relation to the MSF.

On assessment of the association between gender and MSF approximation by maxillary molars roots, our results showed that gender was a statistically significant predictor for the vertical relationship between DB root apex of maxillary third molar and MSF, where the males showed a higher prevalence of type (2) and type (3) while females showed higher prevalence of type (0) and type (1). This indicates that males' molars roots are more close to MSF than females' molars roots. This finding is agreeing with those of Shokri et al. $2014^{34}$ \& Ok et al $2014^{36}$ as both studies found that the frequency of maxillary molars roots penetrating the MSF was significantly higher in males while the frequency of maxillary molar roots not reaching MSF was higher in females. The explanation of this finding could be based on the differences between males and females in their growth pattern with longer teeth roots in males than in females which predispose to MSF invagination ${ }^{34}$. However Kilic et al $2010^{35}$, Pagin et al ${ }^{41}$. 2013\& Shokry et al 2016 ${ }^{40}$ found no correlation between gender and maxillary molars vertical relation to MSF.

Finally which of the assessed types of vertical relationship between MSF and maxillary molar roots is clinically more relevant to maxillary sinus pathosis was not investigated in this study and we recommend further studies to be made for clarification of this point.

\section{CONCLUSIONS}

In the investigated Egyptian sample;

- Maxillary $1^{\text {st }}$ molars roots are the least close to the MSF compared to the other molars roots, while buccal roots of maxillary $2^{\text {nd }}$ molars are highly anticipated for MSF invagination

- The lower the age is the closer are the maxillary $1^{\text {st }}$ molar roots to the MSF

- Males' maxillary $3^{\text {rd }}$ molars are more frequently approximating MSF than females.

\section{REFERENCES}

1. Merriam-Webster's. Medical Desk Dictionary Revised Ed. 2002, pg 49.

2. Standring S. Gray's anatomy: the anatomical basis of clinical practice. 41st ed. London: Elsevier Health Sciences; 2015.

3. Duncavage J. The maxillary sinus: medical and surgical management. New York: Thieme Medical Publishers; 2011.

4. Eberhardt JA, Torabinejad M, Christiansen EL. A computed tomographic study of the distances between the maxillary sinus floor and the apices of the maxillary posterior teeth. Oral Surg Oral Med Oral Pathol. 1992 Mar;73(3):345-6.

5. Jang JK, Kwak SW, Ha JH, Kim HC. Anatomical relationship of maxillary posterior teeth with the sinus floor and buccal cortex. J Oral Rehabil. 2017 Aug;44(8):617-625. 
6. Roque-Torres GD, Ramirez-Sotelo LR, Vaz SL, Bóscolo SM, Bóscolo FN. Association between maxillary sinus pathologies and healthy teeth. Braz J Otorhinolaryngol. 2016 Jan-Feb;82(1):33-8.

7. Hauman CH, Chandler NP, Tong DC. Endodontic implications of the maxillary sinus: a review. Int Endod J 2002 Feb;35(2):127-4.

8. Mehra P, Murad H. Maxillary sinus disease of odontogenic origin. Otolaryngol Clin North Am 2004 Apr;37(2):347-64.

9. Lu Y, Liu Z, Zhang L, Zhou X, Zheng Q, Duan X. Associations between maxillary sinus mucosal thickening and apical periodontitis using cone-beam computed tomography scanning: A retrospective study. J Endod. 2012 Aug;38(8):1069-74.

10. Oberli K, Bornstein MM, von Arx T. Periapical surgery and the maxillary sinus: Radiographic parameters for clinical outcome. Oral Surg Oral Med Oral Pathol Oral Radiol Endod 2007 Jun;103(6):848-53.

11. Iwanaga, Joe et al. Clinical anatomy of the maxillary sinus: application to sinus floor augmentation. Anat Cell Biol. 2019 Mar;52(1):17-24.

12. Cotton TP, Geisler TM, Holden DT, Schwartz SA, Schindler WG. Endodontic applications of cone-beam volumetric tomography. J Endod 2007 Sep;33(9):1121-32.

13. Hamada $\mathrm{Y}$, Kondoh $\mathrm{T}$, Noguchi $\mathrm{K}$, Iino M, Isono H, Ishii H, Mishima A, Kobayashi K, Seto K.. Application of limited cone beam computed tomography to clinical assessment of alveolar bone grafting: a preliminary report. Cleft Palate Craniofac J. 2005 Mar;42(2):128-37.

14. Scarfe WC, Levin MD, Gane D, Farman AG.Use of cone beam computed tomography in endodontics. Int J Dent. 2009;2009:634567.

15. De Vos W, Casselman J, Swennen GR. Cone-beam computerized tomography (CBCT) imaging of the oral and maxillofacial region: a systematic review of the literature. Int J Oral Maxillofac Surg. 2009 Jun;38(6):609-25.

16. Benavides E, Rios HF, Ganz SD, An CH, Resnik R, Reardon GT, Feldman SJ, Mah JK, Hatcher D, Kim MJ, Sohn DS, Palti A, Perel ML, Judy KW, Misch CE, Wang HL. Use of cone beam computed tomography in implant dentistry: the International Congress of Oral Implantologists consensus report. Implant dentistry. 2012 Apr 1;21(2):78-86.

17. Fry RR, Patidar DC, Goyal S, Malhotra A. Proximity of maxillary posterior teeth roots to maxillary sinus and adjacent structures using Denta scan ${ }^{\circledR}$. Indian J Dent. 2016 Sep;7(3):126 -30.
18. Jung YH, Cho BH. Comparison of panoramic radiography and cone beam computed tomography for assessing the relationship between the maxillary sinus floor and maxillary molars. Korean J Oral Maxillofac Radiol 2009;39:69-73.

19. Lang J .Clinical Anatomy of the Nose, Nasal Cavity, and Paranasal Sinuses. New York, USA: Thieme, Medical Publishers: 1989.

20. Mustian WF. The floor of the maxillary sinus and its dental and nasal relation. J Am Dent Assoc 1933: 20: 2175-2187.

21. White \& Pharoah. Oral Radiology: Principles and Interpretation. 6th Edition. Elsevier Health Sciences,2008.

22. Forsberg J. A comparison of the barreling and bisectingangle radiographic techniques in endodontics, Int Endod J 1987; 20:177- 82

23. Tal $\mathrm{H}$ and Moses O. A comparison of panoramic radiography with computed tomography in the planning of implant surgery. Dentomaxillofac Radiol. 1991 Feb;20(1):40-2

24. Freisfeld M, Drescher D, Schellmann B, Schüller H. The maxillary sixth-year molar and its relation to the maxillary sinus. A comparative study between the panoramic tomogram and the computed tomogram. Fortschr Kieferorthop. 1993 Oct;54(5):179-86.

25. Pauwels R, Araki K, Siewerdsen JH, Thongvigitmanee SS. Technical aspects of dental CBCT: state of the art. Dentomaxillofac Radiol. 2015;44(1):20140224.

26. Scarfe WC, Li Z, Aboelmaaty W, Scott SA, Farman AG. Maxillofacial cone beam computed tomography: essence, elements and steps to interpretation. Aust Dent J. 2012 Mar;57 Suppl 1:46-60.

27. Huang C.H. and Brunsvold, M.A. Maxillary sinusitis and periapical abscess following periodontal therapy: A case report using three-dimensional evaluation. J Periodontol. 2006 Jan;77(1):129-34.

28. Brüllmann DD, Schmidtmann I, Hornstein S, Schulze RK. Correlation of cone beam computed tomography (CBCT) findings in the maxillary sinus with dental diagnoses: a retrospective cross-sectional study. Clin Oral Investig. 2012 Aug;16(4):1023-9.

29. Dimitrakopoulosand, I. and Papadaki, M. Foreign body in the maxillary sinus: Report of an unusual case. Quintessence Int. 2008 Sep;39(8):698-701.

30. Koch F, Breil P, Marroquín BB, Gawehn J, Kunkel M. Abscess of the orbit arising $48 \mathrm{~h}$ after root canal treatment of a maxillary first molar. Int Endod J. 2006 Aug;39(8):657-64. 
31. Estrela C, Nunes CA, Guedes OA, Alencar AH, Estrela CR, Silva RG et al. Study of anatomical relationship between posterior teeth and maxillary sinus floor in a subpopulation of the Brazilian central region using cone-beam computed tomography-part 2. Brazilian dental journal. 2016 Feb;27(1):9-15.

32. Kwak HH, Park HD, Yoon HR, Kang MK, Koh KS, Kim HJ. Topographic anatomy of the inferior wall of the maxillary sinus in Koreans. Int J Oral Maxillofac Surg.2004; 33(4):382- 88

33. Jung YH, Cho BH. Assessment of the relationship between the maxillary molars and adjacent structures using cone beam computed tomography. Imaging Sci Dent 2012 Dec; 42(4):219-24.

34. Shokri A, Lari S, Yousefi F, Hashemi L. Assessment of the relationship between the maxillary sinus floor and maxillary posterior teeth roots using cone beam computed tomography. J Contemp Dent Pract 2014;15:618-22.

35. Kilic C, Kamburoglu K, Yuksel SP, Ozen T. An assessment of the relationship between the maxillary sinus floor and the maxillary posterior teeth root tips using dental conebeam computerized tomography. Eur J Dent. 2010 Oct; $4(4): 462-7$

36. Ok E, Gungor E, Colak M, et al. Evaluation of the relationship between the maxillary posterior teeth and the sinus floor using cone-beam computed tomography. Surg Radiol Anat. 2014 Nov; 36(9):907-14.

37. Tian XM, Qian L, Xin X-Z, Wei B , and Gong Y : An Analysis of the Proximity of Maxillary Posterior Teeth to the Maxillary Sinus Using Cone-beam Computed Tomograph. J Endod. 2016 Mar;42(3):371-7.

38. Gu Y, Sun C, Wu D, Zhu Q, Leng D, Zhou Y. Evaluation of the relationship between maxillary posterior teeth and the maxillary sinus floor using cone-beam computed tomography. BMC oral health. 2018 Dec; 18(1):164.
39. Didilescu A, et al. Morphometric analysis of the relationships between the maxillary first molar and maxillary sinus floor.Open Journal of Stomatology. 2012;2:352-357.

40. Shokry Sh, El Wakeel E, AL Sbaih T, Al Otaibi M, AL Osaimi M. Proximity of the Maxillary First Molar Roots and the Maxillary Sinus Floor Using Cone Beam Computed Tomography. RRDS. 2016; 4(2):122-127

41. Pagin O, Centurion BC et al. Maxillary Sinus and Posterior Teeth: Accessing Close Relationship by Cone-beam Computed Tomographic Scanning in a Brazilian Population. J Endod. 2013 Jun; 39(6):748-51.

42. Asthana G, Bhargava S, Parmar GJ. Proximity of Maxillary Sinus Floor to the Roots of Maxillary Molars: A CBCT Evaluation. Endodontology. 2015 Jan 1;27(1).

43. Ariji, Y., Kuroki, T., Moriguchi, S., Ariji, E. and Kanda, S. Age changes in the volume of the human maxillary sinus: A study using computed tomography. Dentomaxillofac Radiol. 1994 Aug; 23(3):163-8

44. Jun, B.C., Song, S.W., Park, C.S., Lee, D.H., Cho, K.J. and Cho, J.H. The analysis of maxillary sinus aeration according to aging process; volume assessment by 3 -dimensional reconstruction by high-resolutional CT scanning. Otolaryngol Head Neck Surg. 2005 Mar;132(3):429-34.

45. Nowak R, Mehlis G. Studies on the state of pneumatization of the sinus maxillaris. Anat Anz. 1975;138(3):143-51.

46. Thomas A, Raman R. A comparative study of the pneumatization of the mastoid air cells and the frontal and maxillary sinuses. AJNR Am J Neuroradiol. 1989 Sep-Oct;10(5 Suppl):S88.

47. Sharan A, Madjar D. Maxillary sinus pneumatization following extractions: a radiographic study. Int J Oral Maxillofac Implants. 2008 Jan-Feb;23(1):48-56.

48. Harorh A, Bocutoglu O. The comparison of vertical height and width of maxillary sinus by means of Waters' view radiograms taken from dentate and edentulous cases. Ann Dent. 1995 Summer-Fall;54(1-2):47-9. 